\title{
Meningioma surgery in younger and older adults: patient profile and surgical outcomes
}

\author{
K. Mariam Slot ${ }^{1,2}$ (D) Jocelyne V. M. Peters ${ }^{1} \cdot$ W. Peter Vandertop ${ }^{1,2} \cdot$ Dagmar Verbaan $^{2} \cdot$ Saskia M. Peerdeman $^{1}$
}

Received: 29 September 2017 / Accepted: 2 December 2017 / Published online: 21 December 2017

(C) The Author(s) 2017. This article is an open access publication

\begin{abstract}
Background Due to increasing life expectancy, the number of older patients harboring a meningioma is expected to increase. We determined whether preoperative variables and postoperative clinical outcome differ between younger and older adults.

Methods Medical records of meningioma patients were retrospectively analyzed. Preoperative variables were age, gender, neurological symptoms, Karnofsky Performance Status (KPS), American Society of Anesthesiologists Physical Status (ASA)-classification and tumor characteristics. Clinical outcome was assessed using complication rates, length of hospital stay and destination after discharge. After 6-12 and 12-18-month KPS, neurological symptoms and Glasgow Outcome Scale (GOS) scores were assessed for older (age $\geq 65$ years) and younger adults (18-65 years) using Mann-Whitney $U$, $T$ test, Pearson's Chi square or Fisher's exact.

Results 89 patients were included ( $23 \geq 65$ years). Before surgery, older patients scored higher on ASA classification $(p=0.003)$ and lower on KPS $(p=0.017)$. There was no significant difference postoperatively in mortality, complications and duration of hospital stay. Less older patients were discharged directly to home compared to younger adults (52 vs $80 \%$, respectively; $p=0.004$ ). In surviving patients, less older subjects had a good recovery (GOS 4-5) at 6-12 months' follow-up compared to younger subjects (64 vs $93 \%$, respectively; $p=0.035$ ). At $12-18$ months, there was no significant difference in good recovery between both age groups ( 82 vs $92 \%$ ).

Conclusion In this cohort, outcome was worse for patients $\geq 65$ years old in terms of discharge destination and good recovery at 6-12 months. At 12-18 months follow-up, older subjects performed not significantly different from younger ones. Careful patient selection seems essential to reach good results in meningioma surgery for patients $\geq 65$ years old.
\end{abstract}

Keywords Meningioma $\cdot$ Elderly $\cdot$ Surgery $\cdot$ Preoperative factors $\cdot$ Outcome $\cdot$ Adults

$\begin{array}{ll}\text { Abbreviations } & \\ \text { WHO } & \text { World Health Organization } \\ \text { KPS } & \text { Karnofsky Performance Status } \\ \text { ASA-classification } & \begin{array}{l}\text { American Society of } \\ \text { Anesthesiologists Physical Status }\end{array} \\ & \begin{array}{l}\text { Classification } \\ \text { GOS }\end{array} \\ \text { Glasgow Outcome Scale }\end{array}$

K. Mariam Slot and Jocelyne V. M. Peters contributed equally.

K. Mariam Slot

k.slot@vumc.nl

1 Neurosurgical Center Amsterdam, VU University Medical Center, PO Box 7057, 1007 MB Amsterdam, The Netherlands

2 Neurosurgical Center Amsterdam, Academic Medical Center, Amsterdam, The Netherlands

\section{Introduction}

The incidence rate of meningiomas increases with age, ranging from 26 to 51 per 100,000 patients [1]. Due to wider use of imaging techniques and an increasing life expectancy, meningiomas are expected to be diagnosed more frequently $[2,3]$. This raises the question whether surgical excision, as first therapeutical option, is as valid for older patients as it is for younger adult patients, and whether the postoperative clinical outcome in these patients, in terms of complications, morbidity and mortality, is comparable to that in younger patients.

As in general surgery, studies regarding the outcome of older patients undergoing meningioma surgery have shown 
conflicting data, which may be attributed to comorbid conditions [4-20]. The aim of this study is to determine whether preoperative variables and postoperative clinical outcome differ between age groups after meningioma surgery.

\section{Materials and methods}

\section{Patient population}

Patients who underwent meningioma surgery at the VU University Medical Center (Amsterdam, the Netherlands), between January 2005 and June 2012 were selected from the hospital database. Patients with a pathologically confirmed World Health Organization (WHO) grade I meningioma were included. Symptomatology was the main indication for surgery, followed by radiological aspects of the tumor. Patients with multiple meningiomas were included if surgery was the only therapy performed. Exclusion criteria were age under 18 years, neurofibromatosis, other intracranial tumors, or radiotherapy directly following surgery. In total, 89 patients were included.

\section{Data collection}

The following data were retrospectively obtained from the medical records: age, gender, neurological symptoms, preoperative Karnofsky Performance Status (KPS), American Society of Anesthesiologists Physical Status Classification (ASA score), tumor location and presence of peritumoral edema on preoperative MR imaging [21, 22]. Postoperative outcome was assessed using the following data: (1) length of hospital stay, (2) destination after discharge, (3) complications within 30 days, and (4) mortality within 30 days. Complications were defined as "unintended and unwanted events or conditions during, or within, 30 days following medical treatment, so harmful for the patient's health that adjustment of medical treatment is needed, or that irreversible damage occurs" [23]. Complication data were collected from the prospective complication database of the department of neurosurgery. Included were neurosurgical complications (i.e., postoperative hemorrhage, wound dehiscence, infection, seizures, CSF leakage, hygroma, hydrocephalus or neurological deficits), as well as systemic complications (i.e., pressure ulcers, multiple organ failure, infections, cardiac arrhythmia, heart failure, thrombo-embolic events, respiratory insufficiency, gastrointestinal complications, kidney failure or metabolic disorders). Urinary tract infection, pneumonia, sepsis and meningitis were defined as clinical symptoms followed by a positive culture. Severity of complications was graded according to the Classification of Surgical Complications according to Dindo [24].

The long-term outcome was assessed at 6-12 months and at 12-18 months after surgery using (1) Glasgow Outcome Scale score (GOS), (2) KPS score and (3) neurological functioning by determining whether the symptoms had resolved, stabilized, improved or worsened at follow-up [25].

\section{Statistical analysis}

Patients were divided into older (age $\geq 65$ years) and younger adult (age 18-65 years) patients. Since older patients are becoming more frequent in clinical practice an additional subgroup analysis of patients over 70 years old was performed. Furthermore, a subgroup analysis for different ASA groups was done. Continuous variables were tested on normal distribution. Differences between age groups in pre- and postoperative factors were analyzed with Mann-Whitney $U$ (not normally distributed continuous variable), $T$ test (normally distributed continuous variable), Pearson's Chi-square (dichotomous or categorical variable with a minimum expected count $>5$ ) or Fisher's exact test (dichotomous or categorical variable with a minimum expected count $<5$ ) using SPSS Statistics 22.

The percentages of follow-up data were calculated from the total number of available follow-ups of both groups. An additional analysis comparing long-term GOS scores (6-12 months, as well as 12-18 months) between age groups was performed in only those patients who survived the period to the specific time of follow-up.

\section{Results}

\section{Preoperative factors}

Symptomatology was the main indication for surgery, followed by radiological aspects of the tumor. Clinical characteristics of the 89 included patients are summarized in Table 1. There was no significant difference in indications for surgery or location of the tumor between the age groups (Table 1). Older patients had higher ASA scores $(p=0.003)$ and lower KPS scores $(p=0.017)$ compared to the younger adults. None of the patients in this cohort had a preoperative KPS lower than 50 .

\section{Postoperative outcome}

Data on postoperative outcome within 30 days after surgery are presented in Table 2. Mortality, complications, and duration of hospital stay did not differ between 
Table 1 Clinical characteristics

\begin{tabular}{|c|c|c|c|c|}
\hline & $N(\%)$ & 18-65 years & $\geq 65$ years & $p$ \\
\hline Patients & $89(100)$ & $66(74)$ & $23(26)$ & \\
\hline \multicolumn{5}{|l|}{ Gender } \\
\hline Female & $61(69)$ & $45(68)$ & $16(70)$ & NS \\
\hline \multicolumn{5}{|l|}{ Age (years) ${ }^{\dagger}$} \\
\hline Mean (SD) & $54.4(12)$ & $49.3(9)$ & $69.2(5)$ & 0.008 \\
\hline \multicolumn{5}{|l|}{ Preoperative KPS } \\
\hline$\leq 60$ & $10(12)$ & $4(6)$ & $6(26)$ & 0.017 \\
\hline$\geq 70$ & 79 (89) & $62(94)$ & $17(74)$ & \\
\hline \multicolumn{5}{|l|}{ ASA } \\
\hline I & $21(24)$ & $19(29)$ & $2(9)$ & 0.003 \\
\hline II & $55(62)$ & $42(64)$ & $13(57)$ & \\
\hline III & $13(15)$ & $5(8)$ & $8(35)$ & \\
\hline \multicolumn{5}{|l|}{ Tumor location } \\
\hline Convexity & $33(37)$ & $24(36)$ & $9(39)$ & NS \\
\hline Falx/tentorium & $16(18)$ & $11(17)$ & $5(22)$ & \\
\hline Skull base & $14(16)$ & $13(20)$ & $1(4)$ & \\
\hline Posterior fossa & $7(8)$ & $6(9)$ & $1(4)$ & \\
\hline Other locations & $6(7)$ & $4(6)$ & $2(9)$ & \\
\hline Multiple tumors & $13(15)$ & $8(12)$ & $5(22)$ & \\
\hline \multicolumn{5}{|l|}{ Preoperative PTBE } \\
\hline Yes & $41(46)$ & $26(39)$ & $15(65)$ & NS \\
\hline \multicolumn{5}{|l|}{ Indication for surgery } \\
\hline Progressive deficit & $26(29)$ & $18(27)$ & $8(35)$ & NS \\
\hline Epilepsy & $15(17)$ & $10(15)$ & $5(22)$ & \\
\hline Tumor growth & $16(18)$ & $13(20)$ & $3(13)$ & \\
\hline Size of tumor & $9(10)$ & $7(11)$ & $2(9)$ & \\
\hline New symptoms & $6(7)$ & $3(5)$ & $3(13)$ & \\
\hline PTBE & $6(7)$ & $5(8)$ & $1(4)$ & \\
\hline Other & $5(6)$ & $5(8)$ & $0(0)$ & \\
\hline Focal neur. deficit & $5(6)$ & $4(6)$ & $1(4)$ & \\
\hline Unknown & $1(1)$ & $1(2)$ & $0(0)$ & \\
\hline
\end{tabular}

KPS Karnofsky Performance Status, ASA American Society of Anesthesiologists' Physical Status Classification, PTBE peritumoral brain edema (PTBE was unknown in $N=1$ of the adult group), $N S$ not significant

${ }^{\dagger}$ Statistical analysis: $t$ test was used

${ }^{*}$ Some patients had one or more meningiomas, which covered more than one location

younger and older subjects. The mortality rate was $2 \%$ : two female patients younger than 65 years of age died within 30 days postoperatively. One patient due to postoperative parenchymal hemorrhage in the midbrain after partial resection of a sphenopetroclival meningioma. The other patient had postoperative cerebrospinal fluid leakage, followed by meningitis, seizures, encephalopathy and respiratory insufficiency. One male patient (69 years old) died in the follow-up period between 12 and 18 months (528 days after surgery). The cause of death was unknown.

The median (interquartile range) length of stay in the hospital was 4 (3-6) days. Of the younger adults, $80 \%$ were discharged directly to home, compared to only $52 \%$ of the older patients $(p=0.004)$. In the $65+$ group, eight $(35 \%)$ patients were transferred to another hospital, whereas for younger adults this was $14 \%$. Five of those eight patients were transferred to another hospital because they needed minor care and home care was not organized yet. Two had a psychiatric history and needed longer observation of mental care, and one had neurological deficits and was evaluated for a nursing home. None of the $65+$ patients were transferred to a medical rehabilitation center.

Subgroup analysis for patients in ASA group I, II and III separately showed no significant difference in complication rate and perioperative mortality between younger and older adults. Discharge location was significantly different between both age groups for ASA II patients $(p=0.006)$. The median (IQ range) duration of hospital stay was 4 (3-5) days and 5 (4-5) days for 18-65 and $\geq 65$ years old ASA I patients, respectively ( $p=0.857)$. For ASA II, this was 4 (3-6) days and 5 (4-10) days $(p=0.036)$, and for ASA III 6 (3-9) days and 4 (3-6) days for 18-65 and $\geq 65$ years old, respectively ( $p=0.683$ ).

No significant difference in complication rate and perioperative mortality between patients 18-70 and $\geq 70$ years old was found. The discharge location was significantly different between those age groups $(p=0.003)$, which is comparable to the findings for patients under and over 65 years old. The median (IQ range) duration of hospital stay was 4 (3-6) days and 7 (5-18) days for $18-70$ and $\geq 70$ years old, respectively.

\section{Long-term outcome}

Long-term follow-up data were available in up to $60 \%$ of the patients. They are presented in Table 3. Neurological symptoms, KPS and GOS scores did not differ between the two age groups at both times of follow-up. In the subgroup analysis for different ASA groups, we found a significant difference between both age groups for KPS at $12-18$ months $(p=0.032)$ for ASA II patients.

An additional analysis in surviving patients, as presented in Table 4, showed a difference in good and moderate recovery at 6-12 months postoperatively between younger and older patients (93 and 7 vs 64 and 36\%, respectively, $p=0.035)$. This difference in good and moderate outcome of surviving patients was not present at follow-up after 12-18 months (92 and $8 \%$ in younger adults vs 82 and $18 \%$ in the older subjects, respectively; $p=0.301$ ). 
Table 2 Postoperative outcome

\begin{tabular}{|c|c|c|c|c|}
\hline & $N(\%)$ & $18-65$ years & $\geq 65$ years & $p$ \\
\hline Patients & $89(100)$ & $66(74)$ & $23(26)$ & \\
\hline \multicolumn{5}{|l|}{ Complications* } \\
\hline None & $42(47)$ & $33(50)$ & $9(39)$ & \multirow[t]{7}{*}{ NS } \\
\hline Grade I & $21(24)$ & $13(20)$ & $8(35)$ & \\
\hline Grade II & $8(9)$ & $6(9)$ & $2(9)$ & \\
\hline Grade IIIa & $4(5)$ & $3(5)$ & $1(4)$ & \\
\hline Grade IIIb & $8(9)$ & $6(9)$ & $2(9)$ & \\
\hline Grade IV & $4(5)$ & $3(5)$ & $1(4)$ & \\
\hline Grade V & $2(2)$ & $2(3)$ & $0(0)$ & \\
\hline Perioperative mortality & $2(2)$ & $2(3)$ & $0(0)$ & NS \\
\hline \multicolumn{5}{|l|}{ Discharge location $^{\dagger}$} \\
\hline Home & $65(73)$ & $53(80)$ & $12(52)$ & \multirow[t]{4}{*}{0.002} \\
\hline Rehabilitation & $2(2)$ & $2(3)$ & $0(0)$ & \\
\hline Other hospital & $17(20)$ & $9(14)$ & $8(35)$ & \\
\hline Nursing home & $3(3)$ & $0(0)$ & $3(13)$ & \\
\hline \multicolumn{5}{|l|}{ Duration of hospital stay* } \\
\hline Median (IQ range) & $4(3-6)$ & $4(3-6)$ & $4(4-7)$ & NS \\
\hline
\end{tabular}

\section{Discussion}

Despite the differences in ASA classification and preoperative KPS, there was no significant difference in mortality, complication rate and long-term outcome between younger and older $(65+)$ adults after surgery for meningioma. As expected, the postoperative clinical outcome 6-12 months after surgery was poorer for $65+$ than for younger adults, but in patients with a follow-up between 12 and 18 months, this difference was no longer present.

ASA-classification is one of the most commonly identified factors associated with mortality after surgery for meningioma [13]. Compared to adults, Bateman et al. found that patients over 70 years old are three times as likely to die in the hospital, but conflicting data for $65+$ have been reported [6-9, 12, 17, 19, 26-42]. In our cohort, the overall 30-day mortality was $2 \%$, which is comparable to results of recent literature. We found no difference between age groups. Poon et al. found poorer functional outcomes in the older patients at 12 months' follow-up compared to younger adult patients [28]. Our study suggests the same for 6-12 months' follow-up, but 12-18 months after surgery clinical outcome was the same for both age groups. This emphasizes the value of longerterm follow-up, providing more insight into recovery time for younger and older adults.
In the literature, data comparing the destination after discharge in older meningioma patients compared to younger adults are limited. Bateman et al. described that older patients were five times more likely to have an adverse outcome, which was defined as either death or discharge to a facility other than home [6]. These findings were reported as independent effects of age, after correction for comorbid medical conditions. Unfortunately, it was not possible to compare our data with these results because 'death' and 'discharge to other facility than home' were combined in a single outcome parameter in Bateman's study. It was not possible to reproduce the specific data on discharge destination. Poon et al. also found that adult patients were discharged to home more often than older patients [28]. Our results confirm this finding. Furthermore, we found that most of the older subjects could not go home straight after surgery, but could go home when minor home care was organized. The same is found after general surgery for older adults. Alexander et al. described that $50.8 \%$ of 592 patients $\geq 75$ years old were discharged home with skilled services or to a skilled nursing facility after abdominal and pelvic cancer surgery [43]. Length of hospital stay after non-elective general surgery is found to be longer for older patients compared to younger adults [44, 45]. Simmonds et al. studied colorectal surgery in elderly patients. After studying 34,194 subjects, they found that elderly patients had an increased frequency of comorbid conditions 
Table 3 Long-term outcome

\begin{tabular}{|c|c|c|c|c|}
\hline & $N(\%)$ & $18-65$ years & $\geq 65$ years & $p$ \\
\hline Total number of patients & $89(100)$ & $66(74)$ & $23(26)$ & \\
\hline \multicolumn{5}{|l|}{ Symptoms 6-12 } \\
\hline New/worse & $6(7)$ & $5(8)$ & $1(4)$ & \multirow[t]{5}{*}{ NS } \\
\hline Persistent & $10(11)$ & $7(11)$ & $3(13)$ & \\
\hline Improved & $16(18)$ & $10(15)$ & $6(26)$ & \\
\hline None & $10(11)$ & $9(14)$ & $1(4)$ & \\
\hline Missing data & $47(53)$ & $35(53)$ & $12(52)$ & \\
\hline \multicolumn{5}{|l|}{ Symptoms $12-18$} \\
\hline New/worse & $11(12)$ & $9(14)$ & $2(9)$ & \multirow[t]{5}{*}{ NS } \\
\hline Persistent & 12 (13) & $9(14)$ & $3(13)$ & \\
\hline Improved & $8(9)$ & $6(9)$ & $2(9)$ & \\
\hline None & $19(21)$ & $15(23)$ & $4(17)$ & \\
\hline Missing data & $39(44)$ & $27(41)$ & $12(52)$ & \\
\hline \multicolumn{5}{|l|}{ KPS 6-12 months } \\
\hline$\leq 60$ & $2(2)$ & $0(0)$ & $2(9)$ & \multirow[t]{3}{*}{ NS } \\
\hline$\geq 70$ & $39(44)$ & $30(45)$ & $9(39)$ & \\
\hline Missing data & $48(54)$ & $36(55)$ & $12(52)$ & \\
\hline \multicolumn{5}{|l|}{ KPS $12-18$ months } \\
\hline$\leq 60$ & $3(3)$ & $1(2)$ & $2(9)$ & \multirow[t]{3}{*}{ NS } \\
\hline$\geq 70$ & $47(53)$ & $38(58)$ & $9(39)$ & \\
\hline Missing data & $39(44)$ & $27(41)$ & $12(52)$ & \\
\hline \multicolumn{5}{|l|}{ GOS $6-12$ months } \\
\hline Death & $2(2)$ & $2(3)$ & $0(0)$ & \multirow[t]{4}{*}{ NS } \\
\hline Moderate disability & $6(7)$ & $2(3)$ & $4(17)$ & \\
\hline Good recovery & 35 (39) & $28(42)$ & $7(30)$ & \\
\hline Missing data & $46(52)$ & $34(52)$ & $12(52)$ & \\
\hline \multicolumn{5}{|l|}{ GOS $12-18$ months } \\
\hline Death & $3(3)$ & $2(3)$ & $1(4)$ & \multirow[t]{4}{*}{ NS } \\
\hline Moderate disability & $5(6)$ & $3(5)$ & $2(9)$ & \\
\hline Good recovery & $45(51)$ & $36(55)$ & $9(39)$ & \\
\hline Missing data & $36(40)$ & $25(38)$ & $11(48)$ & \\
\hline
\end{tabular}

$p$ values were calculated from the total number of available followups

NS not significant, KPS Karnofsky Performance Status, GOS Glasgow Outcome Score

and the incidence of postoperative morbidity and mortality increased progressively with advancing age. However, they concluded that selected elderly patients benefit from surgery since a large proportion survive for at least 2 years, irrespective of their age [46].

Taking into account the differences in course of recovery and destination after discharge, the results of our study suggest that meningioma surgery is well tolerated in patients at high age (both $65+$ and $70+$ ). Thus, age alone need not be a contraindication for surgery. Clinical judgement and operative risk assessment (for which tumor location and degree of tumor vascularity is extremely important) remain to play an important role in the decision- making for surgery. After surgery, older patients need close follow-up and liberal use of rehabilitation, since they need more time to recover from meningioma surgery.

Some shortcomings of this study need to be addressed. All data were retrospectively collected from medical records, and unfortunately some follow-up data for 6-12 months and 12-18 months were missing or inconsistent. These data were missing because (part of) followup took place at the medical center that referred the patient in the first place. There is no reason to assume that the missing data are from patients who performed better or worse than the others. A comparison between the patients who were, and were not, assessed at 6-12 months and 12-18 months follow-up, revealed no significant differences in terms of gender, preoperative KPS, ASA classification, WHO grade and neurosurgical- and systemic complications after surgery. Since the missing follow-up data are missing at random, the results for 6-12 months and 12-18 months after surgery seem representative, although they must be interpreted with caution.

Another shortcoming of this study is the influence of comorbidity. Ideally it would be interesting to compare the two groups of patients after adjustment for comorbidity using for instance regression modeling, but unfortunately the sample size was too small for this adjustment. Therefore, we performed a subgroup analysis per ASA classification for the variables in Tables 2 and 3. This subgroup analysis showed a significant difference in discharge location for ASA II patients. For this ASA group duration of hospital stay and KPS at 12-18 months also turned out to be significantly different between the age groups. ASA II subjects $\geq 65$ years old stayed in the hospital longer and had a lower KPS at 12-18 months compared to younger patients. These differences are not present in the overall analysis (Table 3). Since patient groups are very small for different ASA categories, it is hard to draw conclusion from this subgroup analysis.

As mentioned, a major limitation of this study is the small sample size, which may influence the reliability of the results. Larger series, or pooling of high-quality small series, are needed to confirm our findings.

\section{Conclusion}

Postoperative outcome 30 days and 6-12 months after meningioma surgery, in terms of discharge destination and GOS score, was worse in older surviving patients compared to younger adults. At 12-18 months follow-up, however, older patients reached the same level of recovery as younger adult patients. Complication rate and mortality showed no differences between both age groups during the whole follow-up period. 
Table 4 Long-term GOS for surviving patients only

\begin{tabular}{lcccc}
\hline & $N(\%)$ & $18-65$ years & $\geq 65$ years & $p$ \\
\hline $\begin{array}{l}\text { Number of patients at FU 6-12 months } \\
\text { GOS 6-12 months }\end{array}$ & $41(100)$ & $30(73)$ & $11(27)$ & \\
Moderate disability & $6(15)$ & $2(7)$ & $4(36)$ & 0.035 \\
Good recovery & $35(85)$ & $28(93)$ & $7(64)$ & \\
Number of patients at FU 12-18 months & $50(100)$ & $39(78)$ & $11(22)$ & \\
GOS 12-18 months & & & & \\
Moderate disability & $5(10)$ & $3(8)$ & $2(18)$ & NS \\
Good recovery & $45(90)$ & $36(92)$ & $9(82)$ & \\
\hline
\end{tabular}

FU follow-up, GOS Glasgow Outcome Score, $N S$ not significant
As in all patients, careful patient selection is essential to reach good results in $65+$ patients when considering meningioma surgery. Moreover, it is important to inform those patients and their relatives about the potentially longer period of recovery and temporary discharge to another care facility.

\section{Compliance with ethical standards}

Funding No funding was received for this research.

Conflict of interest All authors certify that they have no affiliations with or involvement in any organization or entity with any financial interest (such as honoraria; educational grants; participation in speakers' bureaus; membership, employment, consultancies, stock ownership, or other equity interest; and expert testimony or patentlicensing arrangements), or non-financial interest (such as personal or professional relationships, affiliations, knowledge or beliefs) in the subject matter or materials discussed in this manuscript.

Ethical approval This study was approved by the local Ethics Committee (registered under IRB00002991/FWA00017598). All procedures performed in studies involving human participants were in accordance with the ethical standards of the institutional and/or national research committee and with the 1964 Helsinki Declaration and its later amendments or comparable ethical standards.

Informed consent For this retrospective study formal consent is not required.

Open Access This article is distributed under the terms of the Creative Commons Attribution 4.0 International License (http://creative commons.org/licenses/by/4.0/), which permits unrestricted use, distribution, and reproduction in any medium, provided you give appropriate credit to the original author(s) and the source, provide a link to the Creative Commons license, and indicate if changes were made.

\section{References}

1. Ostrom QT et al (2015) CBTRUS statistical report: primary brain and central nervous system tumors diagnosed in the United States in 2008-2012. Neuro Oncol 17(Suppl 4):iv1-iv62
2. Kuratsu J, Kochi M, Ushio Y (2000) Incidence and clinical features of asymptomatic meningiomas. J Neurosurg 92:766-770

3. Nakamura M, Roser F, Michel J, Jacobs C, Samii M (2003) The natural history of incidental meningiomas. Neurosurgery 53:62-70 (discussion 70-61)

4. Ackermann RJ, Vogel RL, Johnson LA, Ashley DW, Solis MM (1995) Surgery in nonagenarians: morbidity, mortality, and functional outcome. J Fam Pract 40:129-135

5. Audisio RA, Ramesh H, Longo WE, Zbar AP, Pope D (2005) Preoperative assessment of surgical risk in oncogeriatric patients. Oncologist 10:262-268

6. Bateman BT, Pile-Spellman J, Gutin PH, Berman MF (2005) Meningioma resection in the elderly: nationwide inpatient sample, 1998-2002. Neurosurgery 57:866-872 (discussion 866-872)

7. Boviatsis EJ, Bouras TI, Kouyialis AT, Themistocleous MS, Sakas DE (2007) Impact of age on complications and outcome in meningioma surgery. Surg Neurol 68:407-411 (discussion 411)

8. Caroli M et al (2005) Surgery for intracranial meningiomas in the elderly: a clinical-radiological grading system as a predictor of outcome. J Neurosurg 102:290-294

9. Djindjian M, Caron JP, Athayde AA, Fevrier MJ (1988) Intracranial meningiomas in the elderly (over 70 years old). A retrospective study of 30 surgical cases. Acta Neurochir (Wien) 90:121-123

10. Drummond KJ, Zhu JJ, Black PM (2004) Meningiomas: updating basic science, management, and outcome. Neurologist 10:113-130

11. Kojima Y, Narita M (2006) Postoperative outcome among elderly patients after general anesthesia. Acta Anaesthesiol Scand 50:19-25

12. Patil CG, Veeravagu A, Lad SP, Boakye M (2010) Craniotomy for resection of meningioma in the elderly: a multicentre, prospective analysis from the National Surgical Quality Improvement Program. J Neurol Neurosurg Psychiatry 81:502-505

13. Poon MT, Fung LH, Pu JK, Leung GK (2014) Outcome of elderly patients undergoing intracranial meningioma resection-a systematic review and meta-analysis. Br J Neurosurg 28:303-309

14. Roser F et al (2007) Management of skull based meningiomas in the elderly patient. J Clin Neurosci 14:224-228

15. Suemitsu R et al (2009) The perioperative complications for elderly patients with lung cancer associated with a pulmonary resection under general anesthesia. J Thorac Oncol 4:193-197

16. Bir SC, Konar S, Maiti TK, Guthikonda B, Nanda A (2016) Surgical outcomes and predictors of recurrence in elderly patients with meningiomas. World Neurosurg 90:251-261

17. Konglund A, Rogne SG, Helseth E, Meling TR (2013) Meningioma surgery in the very old-validating prognostic scoring systems. Acta Neurochir (Wien) 155:2263-2271 (discussion 2271) 
18. Sughrue ME et al (2011) Risk factors for the development of serious medical complications after resection of meningiomas. J Neurosurg 114:697-704

19. Grossman R et al (2011) Preoperative Charlson Comorbidity Score predicts postoperative outcomes among older intracranial meningioma patients. World Neurosurg 75:279-285

20. Nakamura M, Roser F, Dormiani M, Vorkapic P, Samii M (2005) Surgical treatment of cerebellopontine angle meningiomas in elderly patients. Acta Neurochir 147:603-610

21. Karnofsky DA (1949) The clinical evaluation of chemotherapeutic agents in cancer. In: MacLeod CM (ed) evaluation of chemotherapeutic agents. Columbia University Press, New York

22. Owens WD, Felts JA, Spitznagel EL Jr (1978) ASA physical status classifications: a study of consistency of ratings. Anesthesiology 49:239-243

23. Marang-van de Mheen PJ, Hanegem N, Kievit J (2005) Effectiveness of routine reporting to identify minor and serious adverse outcomes in surgical patients. Qual Saf Health Care 14:378-382

24. Dindo D, Demartines N, Clavien PA (2004) Classification of surgical complications: a new proposal with evaluation in a cohort of 6336 patients and results of a survey. Ann Surg 240:205-213

25. Jennett B, Bond M (1975) Assessment of outcome after severe brain damage. Lancet 1:480-484

26. Chen $\mathrm{ZY}$ et al (2015) Intracranial meningioma surgery in the elderly (over 65 years): prognostic factors and outcome. Acta Neurochir (Wien) 157:1549-1557 (discussion 1557)

27. Black P, Kathiresan S, Chung W (1998) Meningioma surgery in the elderly: a case-control study assessing morbidity and mortality. Acta Neurochir (Wien) 140:1013-1016 (discussion 1016-1017)

28. Poon MT, Fung LH, Pu JK, Leung GK (2013) Outcome comparison between younger and older patients undergoing intracranial meningioma resections. J Neurooncol 114:219-227

29. Konglund A et al (2013) Outcome following surgery for intracranial meningiomas in the aging. Acta Neurol Scand 127:161-169

30. Pirracchio R et al (2010) One-year outcome after neurosurgery for intracranial tumor in elderly patients. J Neurosurg Anesthesiol 22:342-346

31. Nosova $\mathrm{K}$ et al (2013) Urinary tract infections in meningioma patients: analysis of risk factors and outcomes. J Hosp Infect 83:132-139

32. Awad IA, Kalfas I, Hahn JF, Little JR (1989) Intracranial meningiomas in the aged: surgical outcome in the era of computed tomography. Neurosurgery 24:557-560
33. Arienta C, Caroli M, Crotti F, Villani R (1990) Treatment of intracranial meningiomas in patients over 70 years old. Acta Neurochir (Wien) 107:47-55

34. Cornu $\mathrm{P}$ et al (1990) Intracranial meningiomas in elderly patients. Postoperative morbidity and mortality. Factors predictive of outcome. Acta Neurochir (Wien) 102:98-102

35. Umansky F, Ashkenazi E, Gertel M, Shalit MN (1992) Surgical outcome in an elderly population with intracranial meningioma. J Neurol Neurosurg Psychiatry 55:481-485

36. Mastronardi L et al (1995) Intracranial meningiomas in the 9th decade of life: a retrospective study of 17 surgical cases. Neurosurgery $36: 270-274$

37. Lieu AS, Howng SL (1998) Surgical treatment of intracranial meningiomas in geriatric patients. Kaohsiung $\mathrm{J}$ Med Sci 14:498-503

38. Buhl R, Hasan A, Behnke A, Mehdorn HM (2000) Results in the operative treatment of elderly patients with intracranial meningioma. Neurosurg Rev 23:25-29

39. D'Andrea G, Roperto R, Caroli E, Crispo F, Ferrante L (2005) Thirty-seven cases of intracranial meningiomas in the ninth decade of life: our experience and review of the literature. Neurosurgery 56:956-961 (discussion 956-961)

40. Sacko O et al (2007) Intracranial meningioma surgery in the ninth decade of life. Neurosurgery 61:950-954 (discussion 955)

41. Cohen-Inbar O, Soustiel JF, Zaaroor M (2010) Meningiomas in the elderly, the surgical benefit and a new scoring system. Acta Neurochir (Wien) 152:87-97 (discussion 97)

42. Schul DB et al (2012) Meningioma surgery in the elderly: outcome and validation of 2 proposed grading score systems. Neurosurgery $70: 555-565$

43. Alexander K, Shahrokni A, Mahmoudzadeh Pournaki S, KorcGrodzicki B (2016) Skilled care utilization after abdominal and pelvic cancer surgery in older patients. Eur Geriatr Med 7:438-442

44. Vilches-Moraga A et al. (2017) Baseline characteristics and clinical outcomes of older patients admitted as an emergency to general surgical wards. Salford-POPS-GS. Eur Geriatr Med 8(5-6):499-504

45. St-Louis E et al (2016) The outcomes of the elderly in acute care general surgery. Eur J Trauma Emerg Surg 42:107-113

46. Colorectal Cancer Collaborative Group (2000) Surgery for colorectal cancer in elderly patients: a systematic review. Lancet 356:968-974 